Rhodamine $B$. Add enough sulphuric acid to $3-10 \mathrm{ml}$ of the vanadium(IV) solution $(0.5$ to $6 \mathrm{mMol})$ to yield a normality of $1 \mathrm{~N}$ and dilute to $50 \mathrm{ml}$. Add 4-5 drops of the indicator solution $(0.005 \mathrm{M}$ in water) and titrate with $0.05 \mathrm{~N}$ cerium(IV) sulphate solution (in $1 \mathrm{M}$ sulphuric acid) to a colour change from orange red to yellow.

Iron(II) and vanadium(IV) can be determined in a mixture by first titrating the sum of both by one of the above methods and then titrating $\mathrm{Fe}$ (II) alone in another aliquot either with $\mathrm{Ce}(\mathrm{IV})$ and $\mathrm{N}$-phenyl anthranilic acid as indicator in the presence of $2 \mathrm{M}$ sulphuric acid or with sodium vanadate using the same indicator. $V(I V)$ is calculated from the difference.

Results obtained by the above procedures were in close agreement with the theoretical values.

Attempts to use Xylene Cyanol FF and N-phenyl anthranilic acid as indicators in this titration did not succeed. Tris-bipyridyl iron(II) was also found to work satisfactorily as indicator in the titration of vana$\operatorname{dium}(\mathrm{IV})$ with potassium permanganate if a small amount of phosphoric acid is present in the solution.

Dr. G. N. Rao

Chem. Department

Indian Institute of Technology

New Delhi-29

India

\section{Extraction Studies of Metal Xanthates}

\section{Extraction of Nickel with Ethyl Acetate}

Untersuchung der Extraktion von Metallxanthaten

I. Extraktion von Nickel mit Äthylacetat

\section{A. L. J. Rao and SuRINDER SINGH}

Department of Chemistry, Punjabi University, Patiala, India

Received April 26, 1971

Chloroform and benzene have been widely used for the extraction of nickel and separation from other elements. Potassium ethyl xanthate has been used for the detection of nickel. In the present paper the extraction of nickel xanthate with ethyl acetate is described.

\section{Reagent and Apparatus}

Potassium ethyl xanthate was prepared from distilled alcohol and $\mathrm{CS}_{2}$ [2]. Nickel chloride pure (Canning \& Co.), socium formate (Riedel-de Haen), potassium chloride G.R. (Merck) and B.D.H. distilled ethyl acetate were used. Demineralised water was used throughout the work.

Lamontrel Colorimeter of Photovolt Company, New York, and Philips pH meter were employed.
Extraction Technique. To different aliquots of the metal ion solution $1.5 \mathrm{ml}$ of xanthate reagent (see below) are added and the volume is made to $5 \mathrm{ml}$ with water in a separating funnel to which $5 \mathrm{ml}$ of ethyl acetate are added. The mixture is thoroughly equilibrated for a few min. After settling both the layers are separated. The same process is repeated by adding $5 \mathrm{ml}$ of ethyl acetate to the aqueous layer and the remaining metal is extracted. Both the organic extracts are mixed, diluted to $25 \mathrm{ml}$, an aliquot of it is taken and the colour absorbance is measured using a blue filter (435 to $480 \mathrm{~m} \mu$ ).

For an almost complete extraction $5 \mathrm{ml}$ of ethyl acetate are required in the $\mathrm{pH}$ range $5-9$ and $1.5 \mathrm{ml}$ of xanthate reagent (a mixture of $1 \mathrm{ml}$ of $4 \%$ xanthate and $2 \mathrm{ml}$ of $3 \mathrm{M} \mathrm{KCl}$ or $1 \mathrm{ml}$ of $5 \mathrm{M} \mathrm{HCOONa}$ solutions as salting out agent). As it is, ethyl acetate [1] is soluble in water $\left(8.6 \%\right.$ at $\left.20^{\circ} \mathrm{C}\right)$. When $5 \mathrm{ml}$ of aqueous solution and $5 \mathrm{ml}$ of ethyl acetate are equilibrated, the resulting volumes are $5.5 \mathrm{ml}$ (aq. layer) and 4.5 (organic layer). The addition of salting-out agent reduces the solubility of ethyl acetate and both the layers are of equal volumes.

The applicability of Nernst's distribution law was verified by adding different concentrations of the metal ion and finding out the amount extracted into the organic layer. The results revealed that the distribution law is valid in its simple form over a range of $0.05-5.0 \mathrm{mg}$ of $\mathrm{Ni}$ in $5 \mathrm{ml}$ of solution and $\mathrm{D}$ has been found to be almost 22.25 .

Interferences. Manganese, aluminium, zinc, cadmium, chromate, molybdate and tungstate do not interfere and hence nickel can be extracted and determined in the presence of these metals. Copper is also extracted but can be masked with thiourea. The method is quite sensitive and simple and the extract can be used directly for the estimation or even microdetermination of nickel. As chromium remains in the aq. layer under these conditions the same method may be used for the analysis of $\mathrm{Ni}+\mathrm{Cr}$. Extension of this method making use of the extraction of the metal pyridine xanthate complexes and thin layer chromatographic separation of mixtures of ions as xanthates is under progress.

\section{References}

1. Morrison and Frieser: Solvent extraction in analytical chemistry, p. 253. New York: John Wiley and Sons Inc. 1965.

2. Welcher: Organic analytical reagents, Vol. IV, p. 97. New York: Van Nostrand Co. Inc. 1961.

Dr. A. L. J. Rao

Department of Chemistry

Punjabi University

Patiala, India 